\title{
Successful treatment of clear cell carcinoma of ovary during pregnancy: a case report
}

\author{
Preethi Ashok*, Kalaichelvi Kannan
}

Department of Medical Oncology, Madras Medical College, Chennai, Tamil Nadu, India

Received: 02 June 2021

Accepted: 14 June 2021

\author{
*Correspondence: \\ Dr. Preethi Ashok, \\ E-mail: dr.preethi.ashok@gmail.com
}

Copyright: (C) the author(s), publisher and licensee Medip Academy. This is an open-access article distributed under the terms of the Creative Commons Attribution Non-Commercial License, which permits unrestricted non-commercial use, distribution, and reproduction in any medium, provided the original work is properly cited.

\begin{abstract}
The incidence of malignant ovarian tumor is rare during pregnancy. Most women hope to maintain the pregnancy and preserve fertility thus increasing the need for standard guidelines regarding surgery and chemotherapy for safe oncologic and fetal outcomes. Here we present a 30-years-old primigravida, diagnosed with bilateral ovarian mass during routine ultrasound imaging at 8 weeks of gestation. CA125 was $14.2 \mathrm{U} / \mathrm{ml}$. MRI pelvis taken at 13 weeks showed bilateral complex cystic masses with internal septations. The patient underwent bilateral salphingo-oopherectomy and infracolic omentectomy during $18^{\text {th }}$ week of gestation, the histopathology showing clear cell carcinoma with capsular invasion and microscopic omental deposit thus staged as IIIA. She was planned for adjuvant chemotherapy comprising of paclitaxel and carboplatin during the $21^{\text {st }}$ week along with serial ultrasounds for fetal monitoring. After 5 cycles, at 37 weeks of gestation, she was taken up for elective LSCS followed by completion of surgery for ovarian malignancy, that is, hysterectomy with bilateral pelvic lymphadectomy. Endometrium showed gestational changes with all lymph nodes being negative for tumor deposits. A healthy male child weighing $3.4 \mathrm{~kg}$ was delivered. She was given $6^{\text {th }}$ cycle of chemotherapy post-surgery and two years later, mother and baby are doing well and on regular follow up. Thus, the successful treatment of clear cell ovarian carcinoma in this woman with safe pregnancy outcomes can be attributed to timely diagnosis and feasibility of surgery and chemotherapy during second trimester.
\end{abstract}

Keywords: Ovarian cancer, Pregnancy, Clear cell carcinoma, Chemotherapy, Staging

\section{INTRODUCTION}

The incidence of ovarian tumors during pregnancy is 2.4$5.7 \%$, of which $5 \%$ is malignant. ${ }^{1-3}$ The occurrence of ovarian clear cell carcinoma complicating pregnancy is a rare event, accounting to $1-1.5 \%$ only. The tumor, diagnosed most commonly during routine antenatal ultrasound, is responsible for early diagnosis and management of asymptomatic ovarian tumors. Most women hope to maintain the pregnancy and preserve fertility thus increasing the need for standard guidelines regarding surgery and chemotherapy for safe oncologic and fetal outcomes. Here we present a case of clear cell carcinoma of ovary diagnosed incidentally during early pregnancy and presented in our OPD, Department of
Medical Oncology, Madras Medical College and Rajiv Gandhi Government General Hospital, Chennai. The aim of the study was to establish the safety of chemotherapy in second trimester of pregnancy in carcinoma patients.

\section{CASE REPORT}

A thirty-years-old primigravida, with regular menstrual history and married since one year, presented with history of amenorrhea for 1 month and positive urine pregnancy test. She had undergone routine ultrasound imaging which incidentally showed bilateral ovarian mass with gestational sac of size 8 weeks 5 days (Figure 1). Tumor markers were reported as follows: CA-125- $14.2 \mathrm{U} / \mathrm{ml}$, CEA- 1.41 ng/ml, CA 19.9- 29.05 U/ml, LDH-302 U/l, 
beta-HCG- $88768.2 \mathrm{mIu} / \mathrm{ml}$. After four weeks, MRI pelvis showed bilateral complex cystic mass lesions, $8.5 \times 7.3 \times 6.2$ $\mathrm{cm}$ in right adnexa and $9.7 \times 6.3 \times 4.9 \mathrm{~cm}$ in left adnexa, both with internal septations along with single live gestation of 13-14 weeks maturity (Figure 2). A month later, she underwent bilateral salphingo-oopherectomy with infracolic omentectomy during the $18^{\text {th }}$ week of gestation. Per op findings included bilateral mass of approximately $7 \times 7 \mathrm{~cm}$ of variable consistency with cystic areas and papillary excrescences noted arising from the ovaries.
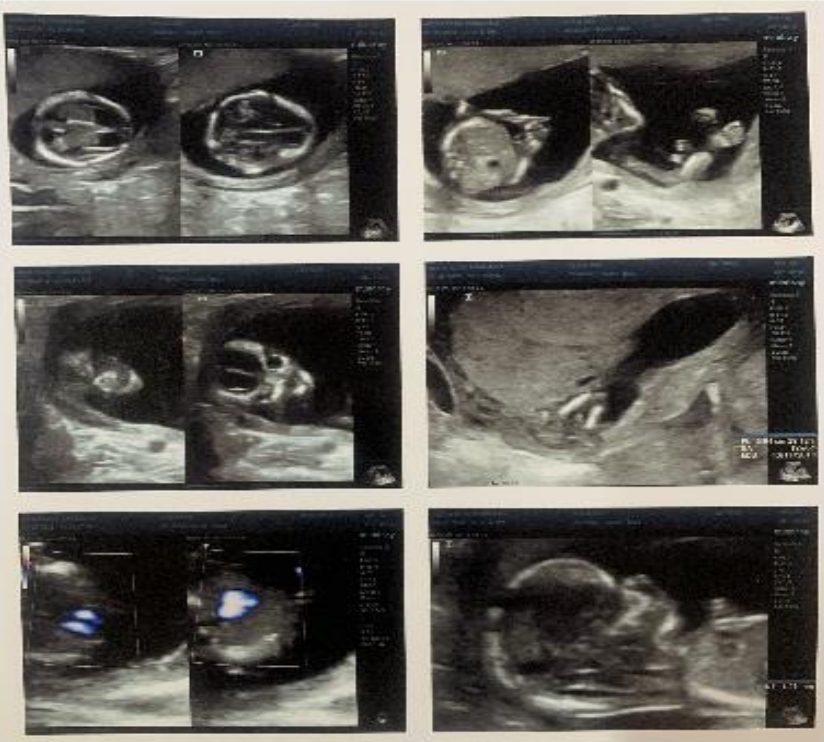

Microscopically, bilateral malignant ovarian neoplasm was seen with malignant epithelial cells, arranged in glandular and papillary pattern thus the impression being malignant surface epithelial tumor-clear cell carcinoma. There was evidence of capsular invasion with the omentum showing microscopic tumor infiltration thus staged as IIIA. Immunohistochemistry showed positive CK7 and negative CK20. Post-surgery, she presented in our department during the $21^{\text {st }}$ week of gestation.
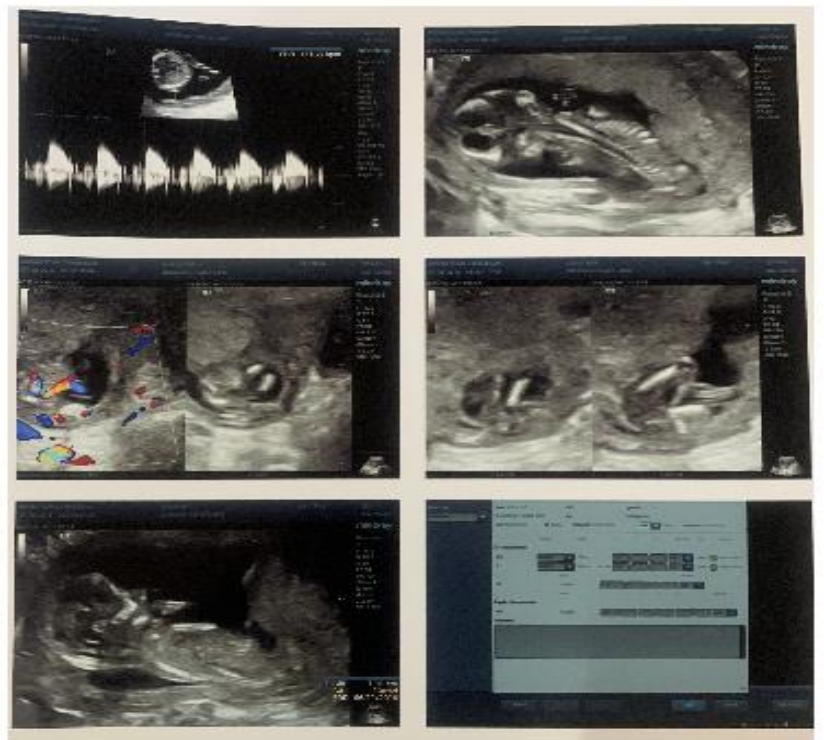

Figure 1: Ultrasound pelvis taken at 8 weeks of gestation.
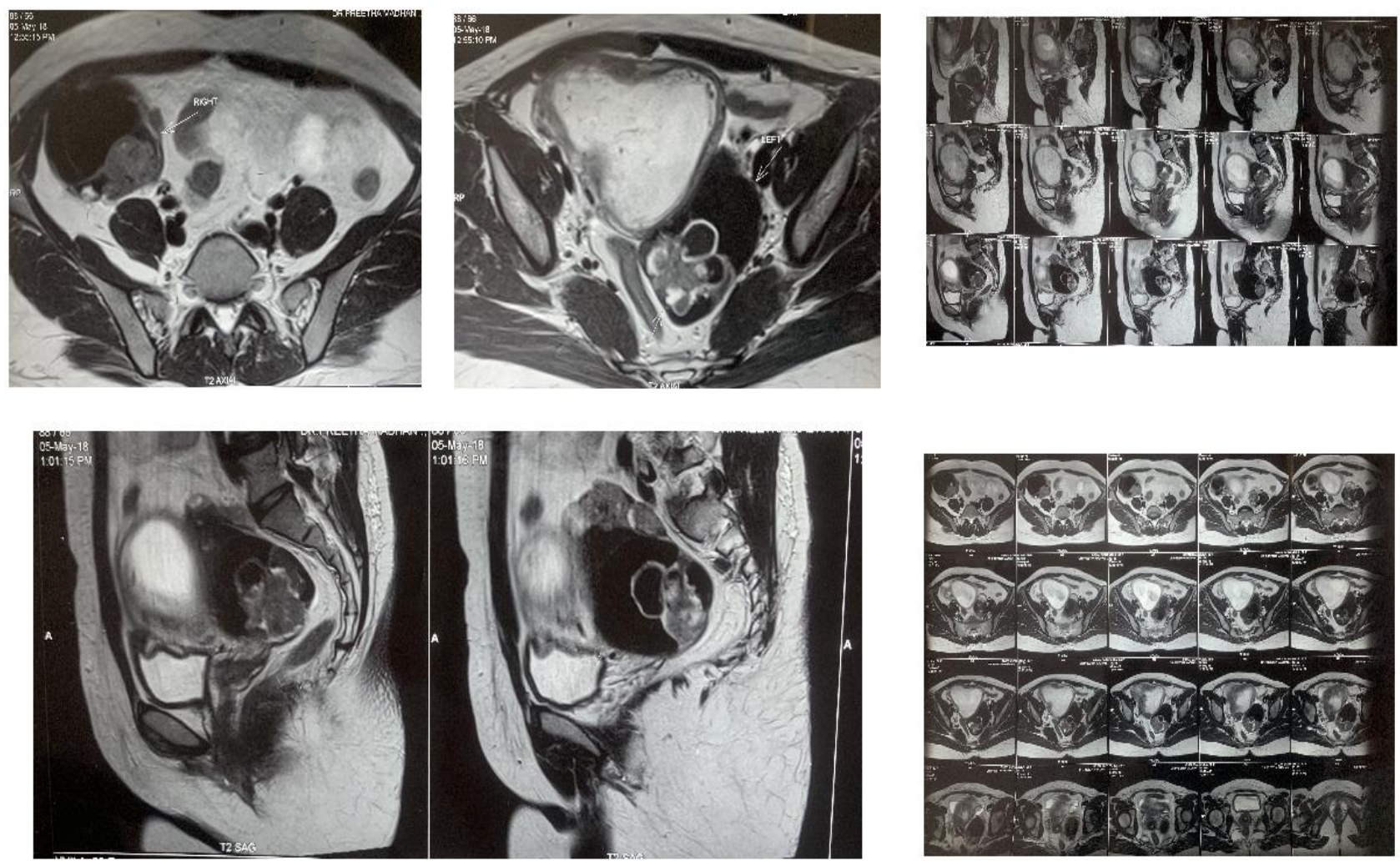

Figure 2: MRI abdomen and pelvis taken at 13 weeks of gestation. 


\section{Management}

In our department, she presented with good performance status and was found to have a 20 weeks gestation size uterus upon examination and a health post-surgical scar. Her blood investigations including complete blood count, liver and renal function tests were normal. Her viral markers and thyroid function tests were found to be normal. She was advised weekly ultrasound for fetal monitoring and was started on adjuvant chemotherapy comprising of injection paclitaxel $260 \mathrm{mg}$ and injection carboplatin $450 \mathrm{mg}$, both on day 1 every 3 weeks from the $21^{\text {st }}$ week of gestation. After completion of 5 cycles at 37 weeks of gestation, she was planned for elective LSCS followed by completion of surgery for ovarian malignancy, that is, hysterectomy with bilateral pelvic lymphadenectomy. The post LSCS endometrial biopsy showed gestational changes along with bilateral lymph nodes showing no malignant deposits. Two weeks after LSCS, she was given the $6^{\text {th }}$ cycle of chemotherapy and is on regular follow up ever since. She had delivered a healthy male baby weighing $3.4 \mathrm{~kg}$ with APGAR score of $8 / 10$ at $1 \mathrm{~min}$ and $9 / 10$ at 5 min after birth. The baby had bilateral hydroureteronephrosis at birth. The baby is on regular follow up with a paediatrician and he is immunised till date.

\section{DISCUSSION}

Primary carcinoma of the ovary most commonly occurs in women with low parity during the latter part of their reproductive years. Most pregnant women with ovarian masses present with almost no symptoms. This asymptomatic nature of this disease makes diagnosis difficult at an early stage. An ultrasound sonogram, being a routine method for evaluating fetal status during pregnancy, can be used for early detection of an incidental ovarian tumor. ${ }^{4}$ The widespread use of routine prenatal ultrasound and higher frequency of caesarean section in recent times have contributed to the early incidental diagnosis of an ovarian tumor complicating pregnancy.

The incidence of ovarian tumor overall during pregnancy is $1 / 300$ to $1 / 556$ pregnancies. ${ }^{5-7}$ Amongst this, the incidence of malignant ovarian tumors complicating pregnancy is $1 / 15000$ to $1 / 32000$ in most reports. ${ }^{4,8}$ The histological distribution of ovarian tumors during pregnancy appears to be similar to those for non-pregnant women according to several studies. ${ }^{4-11}$ In white women, the most common ovarian tumor is dysgerminoma which co-exists with pregnancy, constituting around $25-30 \%$ of all reported ovarian cancers. ${ }^{9,12,13}$

The detection of adnexal masses is very common in the first and second trimester of pregnancy due to the widespread use of routine antenatal ultrasounds. Ultrasound has high sensitivity (96.8\%) and specificity $(77 \%)$ in differentiating benign from malignant ovarian tumors. ${ }^{14}$ An adnexal mass, more than $6 \mathrm{~cm}$ in size, with a complex structure, with or without ascites, or persisting for more than 16 weeks of gestation, has to be taken up for surgical management to obtain a final histological diagnosis and ruling out malignancy. ${ }^{15}$ An adnexal mass smaller than $5 \mathrm{~cm}$, showing no complexity and no specific symptoms can be followed up with serial ultrasound screening. ${ }^{16}$

If surgical intervention is planned during pregnancy, it should be performed during the safest period of pregnancy, preferably during the second trimester, when the risk of spontaneous abortion, and hormonal dependence on the corpus luteum is reduced. If an ovarian mass with low suspicion of malignancy, is identified in first trimester, surgery can be delayed until 16-18 weeks of gestation by which time the functional cysts would have resolved in most cases. ${ }^{17}$ The rate of spontaneous abortion after surgery in first trimester is $10 \% .^{18}$ An ovarian mass identified in the third trimester can be managed by waiting for fetal maturity if there's low clinical suspicion of malignancy but there's a risk of premature labour and poor pregnancy outcome if surgery is attempted in third trimester. ${ }^{19,20}$

Management of ovarian cancer complicating pregnancy include surgery with staging laparotomy, debulking surgery and adjuvant chemotherapy or a tissue diagnosis with upfront chemotherapy which is followed by subsequent debulking surgery. For advanced disease, the principle of adequate staging and debulking surgery is similar to that used for a non-pregnant woman. In case of early stage, unilateral oopherectomy or adnexectomy with appropriate staging would be adequate. It is imperative to use conservative surgical strategies to maintain pregnancy in cases of borderline tumors or germ cell tumors. However, there are no clear definitive guidelines for the management of ovarian cancer during pregnancy.

Radiation exposure to the fetus can pose several threats while using higher imaging modalities for diagnosis or staging of disease. The most vulnerable period for radiation induced Central nervous system damage is 8-15 weeks after conception. Radiation exposure can lead to microcephaly, intellectual deficits, mental retardation and even induction of childhood malignancies. ${ }^{21}$ Hence recommendation is to use magnetic resonance imaging (MRI) in pregnant women if deemed clinically necessary. ${ }^{22,23}$ It is even safer to delay MRI to the second trimester since there is a theoretical safety concern over tissue heating caused by radiofrequency pulses.

Tumor markers are of limited significance in pregnancy for diagnostic purposes since serum CA125 levels may be raised in normal pregnancy with a peak in trimester and return to normal in second trimester. ${ }^{24,25}$

Once the diagnosis of ovarian carcinoma is substantiated, the management is dependent on the stage of the disease, the gestational age, desire for future fertility and the mother $\mathrm{s}$ wish to continue with the pregnancy. Multidisciplinary care is recommended and management 
is case dependent. The potential effects of the disease on the mother and the fetus, the loss of future fertility and the serious life-threatening potential of ovarian cancer and the limitations of diagnostic and therapeutic procedures for the disease during pregnancy have to be discussed with the patient while considering therapeutic termination of pregnancy. ${ }^{26}$

If diagnosed in early stages, staging laparotomy and salpingo-oopherectomy alone, followed by close observation of mother and the fetus with a multidisciplinary setup will be sufficient. In case of advanced disease diagnosed in early pregnancy, therapeutic termination of pregnancy should be strongly considered. ${ }^{19}$ If the patient wants to continue pregnancy, strategic multidisciplinary treatment including chemotherapy should be offered.

Paclitaxel, along with platinum containing agents are the primary chemotherapeutic agents currently being used. Though cisplatin is widely used, carboplatin has shown improved tolerance and equal efficacy. ${ }^{27}$ All chemotherapeutic agents are teratogenic and hence not used in first trimester. ${ }^{28}$ Some of the other important issues to be considered are the mother a health, transplacental transmission of cytotoxic drugs, the effects on the fetus, the potential long-term sequelae in the offspring and the effect of pregnancy on the pharmacology of the chemotherapy drug.

The side effects of carboplatin include myelosuppression, nephrotoxicity and neurotoxicity while paclitaxel may cause neurotoxicity, myelosuppression and in rare cases, fatal anaphylaxis. ${ }^{29}$ The teratogenic effects of carboplatin and paclitaxel have not been specifically explained though studies in rats have shown carboplatin to be embryotoxic, causing intrauterine death and congenital malformations like external, internal and skeletal anomalies in fetus when administered in early organogenesis period. ${ }^{30}$ Carboplatin also showed to inhibit fetal growth and reduce brain weight in rats. Paclitaxel administered in early pregnancy in rats, may cause craniofacial malformations, diaphragmatic hernias, kidney and cardiovascular defects. ${ }^{31}$ But carboplatin and paclitaxel did not affect postnatal differentiation like behavioural development, learning ability, motor activity, memory or emotional development. ${ }^{32,33}$

Chemotherapy is contraindicated in first trimester of pregnancy. Even in second or third trimester, the eyes, hematopoietic system and central nervous system remain vulnerable to chemotherapy drug exposure. ${ }^{34}$ No long term studies are available to analyse the effect on children exposed to chemotherapy in utero. ${ }^{29,35}$ Potential long term effects may include comprised physical and neurological development, increased risk of mutagenesis of germ line tissues and hence malignancies. ${ }^{35}$ This warrants a long term surveillance of these children and the patient should be properly counselled with regard to this. Breast feeding is contraindicated while on cytotoxic chemotherapy.
For nonepithelial ovarian cancers, BEP, cisplatinetoposide and cisplatin-vinblastine-bleomycin chemotherapy may also be used. Intraperitoneal chemotherapy is best used after cytoreductive surgery in stage III ovarian tumors. ${ }^{36}$

Studies comparing pregnancy outcomes in women with ovarian tumors showed the increased incidence of deliveries by caesarean section. Blood transfusion, hysterectomy and postpartum stay $>5$ days have been reported as well. Hypothetically, it has been suggested that maternal ovarian cancer might cause compromised hemodynamic alterations in blood flow to fetus and increased chances of fetal growth retardation and still birth. But there is no substantial evidence to support this hypothesis. Taxane and platinum-based chemotherapy has been found to be safe and well tolerated and not associated with major fetal adversities if administered during second and third trimester. ${ }^{19,24,28}$

Majority of the cases diagnosed during pregnancy have been early stages hence a good prognosis has been observed. There is no evidence to state that pregnancy has a beneficial or an adverse effect on survival outcomes. ${ }^{37,38}$

\section{CONCLUSION}

Currently, there are no definitive guidelines for management of ovarian cancer during pregnancy. Hence it is difficult to assess the true outcome of treatment which includes both maternal and fetal survival. Early detection is the key to optimal management of ovarian tumor during pregnancy. A multidisciplinary team is of utmost importance for proper decision making with respect to maintaining pregnancy and fertility for safe oncologic and fetal outcomes. Management is case dependant. Surgery and chemotherapy may be offered to the patient during second and third trimester of pregnancy after taking into account the stage of the disease, patient s desire to continue pregnancy and the potential effects of the disease and treatment on pregnancy and offspring.

Funding: No funding sources Conflict of interest: None declared

Ethical approval: Not required

\section{REFERENCES}

1. Farahmand SM, Marchetti DL, Asirwatham JE, Dewey MR. Ovarian endodermal sinus tumor associated with pregnancy: review of the literature. Gynecol Oncol. 1991;41(2):156-60.

2. Whitecar MP, Turner S, Higby MK. Adnexal masses in pregnancy: a review of 130 cases undergoing surgical management. Am J Obstet Gynecol. 1999;181(1):19-24.

3. Jacob JH, Stringer CA. Diagnosis and management of cancer during pregnancy. Semin Perinatol. 1990;14(1):79-87. 
4. Zanotti KM, Belinson JL, Kennedy AW. Treatment of gynecologic cancers in pregnancy. Semin Oncol. 2000;27(6):686-98.

5. Lavery JP, Koontz WL, Layman L, Shaw L, Gumpel U. Sonographic evaluation of the adnexa during early pregnancy. Surg Gynecol Obstet. 1986;163(4):31923.

6. Hogston P, Lilford RJ. Ultrasound study of ovarian cysts in pregnancy: prevalence and significance. $\mathrm{Br} \mathrm{J}$ Obstet Gynaecol. 1986;93(6):625-8.

7. Hopkins MP, Duchon MA. Adnexal surgery in pregnancy. J Reprod Med. 1986;31(11):1035-7.

8. Elit L, Bocking A, Kenyon C, Natale R. An endodermal sinus tumor diagnosed in pregnancy: case report and review of the literature. Gynecol Oncol. 1999;72(1):123-7.

9. Dgani R, Shoham Z, Atar E, Zosmer A, Lancet M. Ovarian carcinoma during pregnancy: a study of 23 cases in Israel between the years 1960 and 1984. Gynecol Oncol. 1989;33(3):326-31.

10. Copeland LJ, Landon MB. Malignant disease in pregnancy. In: Gabbe SG, Niebyl JR, Simpson JL, eds. Obstetrics, Normal And Problem Pregnancies. 3rd ed. New York, NY: Churchill Livingstone; 1996: 1155-1181.

11. Behtash N, Karimi ZM, Modares GM, Ghaemmaghami F, Mousavi A, Ghotbizadeh F. Ovarian carcinoma associated with pregnancy: a clinicopathologic analysis of 23 cases and review of the literature. BMC Pregnancy Childbirth. 2008;8:3.

12. Bakri YN, Ezzat A, Akhtar, Dohami, Zahrani. Malignant germ cell tumors of the ovary. Pregnancy considerations. Eur J Obstet Gynecol Reprod Biol. 2000;90(1):87-91.

13. Williams SD, Gershenson DM, Horowitz CJ. Ovarian germ-cell tumors. In: Hoskins WJ, Perez CA, Young RC, eds. Principles And Practice Of Gynaecologic Oncology. Philadelphia, PA: Lippincott; 1996: $987-$ 1001.

14. Lerner JP, Timor TIE, Federman A, Abramovich G. Transvaginal ultrasonographic characterization of ovarian masses with an improved, weighted scoring system. Am J Obstet Gynecol. 1994;170(1):81-5.

15. Dudkiewicz J, Kowalski T, Grzonka D, Czarnecki M. Ovarian tumors in pregnancy. Ginekol Pol. 2002;73(4):342-5.

16. Katz VL, Watson WJ, Hansen WF, Washington JL. Massive ovarian tumor complicating pregnancy. A case report. J Reprod Med. 1993;38(11):907-10.

17. Pitynski K, Basta A, Szczudrawa A, Opławski M. Ovarian tumors in pregnancy in the material of the Department of Gynecology and Oncology Collegium Medicum of Jagiellonian University in Cracow. Ginekol Pol. 2002;73(4):371-5.

18. Ueda M, Ueki M. Ovarian tumors associated with pregnancy. Int J Gynaecol Obstet. 1996;55(1):59-65.

19. Agarwal N, Parul, Kriplani A, Bhatla N, Gupta A. Management and outcome of pregnancies complicated with adnexal masses. Arch Gynecol Obstet. 2003;267(3):148-52.
20. Grendys EC, Barnes WA. Ovarian cancer in pregnancy. Surg Clin North Am. 1995;75(1):1-14.

21. Lowe SA. Diagnostic radiography in pregnancy: risks and reality. Aust NZJ Obstet Gynaecol. 2004;44:1916.

22. Shellock FG, Kanal E. Policies, guidelines, and recommendations for MR imaging safety and patient management. SMRI Safety Committee. J Magn Reson Imaging. 1991;1(1):97-101.

23. ACOG Committee on Obstetric Practice. ACOG Committee Opinion. Number 299, September 2004 (replaces No. 158, September 1995). Guidelines for diagnostic imaging during pregnancy. Obstet Gynecol. 2004;104(3):647-51.

24. Otton G, Higgins S, Phillips KA, Quinn M. A case of early-stage epithelial ovarian cancer in pregnancy. Int J Gynecol Cancer. 2001;11(5):413-7.

25. Kobayashi F, Sagawa N, Nakamura K, Nonogaki M, Ban C, Fujii S, Mori T. Mechanism and clinical significance of elevated CA 125 levels in the sera of pregnant women. Am J Obstet Gynecol. 1989;160(3):563-6.

26. Machado F, Vegas C, Leon J, Perez A, Sanchez R, Parrilla JJ, et al. Ovarian cancer during pregnancy: analysis of 15 cases. Gynecol Oncol. 2007;105(2):446-50.

27. Ghaemmaghami F, Hasanzadeh M. Good fetal outcome of pregnancies with gynecologic cancer conditions: cases and literature review. Int J Gynecol Cancer. 2006;16(1):225-30.

28. Tabata T, Nishiura K, Tanida K, Kondo E, Okugawa $\mathrm{T}$, Sagawa N. Carboplatin chemotherapy in a pregnant patient with undifferentiated ovarian carcinoma: case report and review of the literature. Int $\mathrm{J}$ Gynecol Cancer. 2008;18(1):181-4.

29. Leslie KK. Chemotherapy and pregnancy. Clin Obstet Gynecol. 2002;45(1):153-64.

30. Ozols RF, Bundy BN, Greer BE, Fowler JM, Clarke $\mathrm{PD}$, Burger RA, et al. Phase III trial of carboplatin and paclitaxel compared with cisplatin and paclitaxel in patients with optimally resected stage III ovarian cancer: a Gynecologic Oncology Group study. J Clin Oncol. 2003;21(17):3194-200.

31. Kai S, Kohmura H, Ishikawa K, Takeuchi Y, Ohta S, Kuroyanagi K, et al. Reproduction studies of carboplatin (II)--Intravenous administration to rats during the period of fetal organogenesis. J Toxicol Sci. 1988;13(2):35-61.

32. Kai S, Kohmura H, Ishikawa K, Makihara Y, Ohta S, Kawano S, et al. Teratogenic effects of carboplatin, an oncostatic drug, administered during the early organogenetic period in rats. $\mathrm{J}$ Toxicol Sci. 1989;14(2):115-30.

33. Kai S, Kohmura H, Hiraiwa E, Koizumi S, Ishikawa K, Kawano S, et al. Reproductive and developmental toxicity studies of paclitaxel. (III)--Intravenous administration to rats during the perinatal and lactation periods. J Toxicol Sci. 1994;19(1):93-111.

34. Williams SF, Bitran JD. Cancer and pregnancy. Clin Perinatol. 1985;12(3):609-23. 
35. Hubalek M, Smekal SC, Zeimet AG, Sergi C, Brezinka C, Mueller HE, Marth C. Chemotherapeutic treatment of a pregnant patient with ovarian dysgerminoma. Arch Gynecol Obstet. 2007;276(2):179-83.

36. Brewer M, Kueck A, Runowicz CD. Chemotherapy in pregnancy. Clin Obstet Gyneco.1 2011;54(4):60218.

37. Patsner B, Mann WJ, Chumas J. Primary invasive ovarian adenocarcinoma with brain and placental metastases: a case report. Gynecol Oncol. 1989;33:112-5.

38. Ishioka S, Hayashi T, Endo T, Baba T, Honma H, Saito T. Advanced epithelial ovarian carcinoma during pregnancy. Int J Clin Oncol. 2007;12(5):3758 .

Cite this article as: Ashok P, Kannan K. Successful treatment of clear cell carcinoma of ovary during pregnancy: a case report. Int J Reprod Contracept Obstet Gynecol 2021;10:2872-7. 